\title{
0768 CHILDHOOD SCALD PREVENTION: IMPROVEMENT OF ELECTRIC RICE COOKER
}

T Yamanaka* Correspondence: National Institute of Advanced Industrial Science and Technology, Tokyo Waterfront, 2-3-26, Aomi, Koto, Tokyo, 135-0064, Japan

10.1136/ip.2010.029215.768

A large number of childhood scald injuries due to electric devices such as an electric rice cooker, an electric pot and a clothes iron occurs at home in Japan. An electric rice cooker is very popular consumer product in Japan since many Japanese people live on rice and then preventing scald injuries due to electric rice cookers is important. Scald injuries due to electric rice cookers are caused by steam with high temperature. According of our investigation, commercialised rice cookers discharge steam with temperature of around $98^{\circ} \mathrm{C}$ especially when they are boiling rice. In 2006, Childhood Injury Prevention Engineering Council (CIPEC) asked an electric company to improve safety of electric rice cookers by presenting statistical data and detailed situation data of injury due to electric rice cookers based on a hospital-based injury surveillance system that CIPEC developed. To reduce risk of scald injuries, the electric company developed a new mechanism of steam discharge in which the temperature of steam is cooled to below $50^{\circ} \mathrm{C}$ before the steam is discharged. It is well known that the risk of scald injuries is reduced significantly by decreasing the temperature to less than $50^{\circ} \mathrm{C}$. The cooling mechanism consists of a fan that can reduce steam temperature by changing the energy of steam with high temperature into the rotational kinetic energy of the fan. A new type of electric rice cooker with this cooling mechanism was commercialised in June 2009. 